10

\title{
Влияние УФ облучения на формирование молекулярных кластеров серебра и их стабилизация в растворах, композиционных и оксидных покрытиях
}

\author{
(C) Е.К. Евстропьев ${ }^{1}$, Н.В. Никоноров ${ }^{2}$, А.С. Саратовский ${ }^{2}$, Д.П. Данилович ${ }^{1}$ \\ ${ }^{1}$ Санкт-Петербургский государственный технологический институт (Технический университет), \\ 190013 Санкт-Петербург, Россия \\ ${ }^{2}$ Университет ИТМО, \\ 197101 Санкт-Петербург, Россия \\ e-mail: evstropiev@bk.ru
}

Поступила в редакцию 10.02.2020 г.

В окончательной редакции 10.02.2020 г.

Принята к публикации 19.02.2020 г.

\begin{abstract}
Исследовано влияние УФ облучения на формирование молекулярных кластеров серебра в водных растворах, содержащих нитраты серебра, цинка, магния и поливинилпирролидон. При исследовании растворов и покрытий были использованы методы оптической и люминесцентной спектроскопии, изучение морфологии покрытий осуществлялось методом электронно-микроскопического анализа. Показано, что облучение существенно ускоряет процессы восстановления ионов серебра и образование молекулярных кластеров и наночастиц серебра, стабилизированных поливинилпирролидоном.
\end{abstract}

Ключевые слова: раствор, люминесценция, $\mathrm{Ag}$ молекулярные кластеры, наночастица.

DOI: $10.21883 /$ OS.2020.06.49399.42-20

\section{Введение}

Наличие серебра в составе различных материалов (стекол [1,2], полимеров [3], покрытий [4]) оказывает существенное влияние на их структуру и спектральнолюминесцентные, фотокаталитические и бактерицидные свойства [1-4].

Фоточувствительность соединений серебра хорошо известна, и эта особенность используется для контролируемого синтеза молекулярных кластеров [5] и наночастиц [6,7] серебра. При УФ облучении в растворах происходит восстановление ионов $\mathrm{Ag}^{+}$с последующим образованием и ростом наночастиц серебра. Этот процесс сопровождается появлением в спектрах поглощения плазмонной полосы поглощения наночастиц серебра, увеличением ее интенсивности и постепенным сдвигом в длинноволновую область спектра [8]. Наночастицы серебра, формирующиеся при фотовосстановлении ионов $\mathrm{Ag}^{+}$, имеют сферическую форму, а их размер может изменяться в широких пределах $(5-70 \mathrm{~nm})[9]$.

Молекулярные кластеры серебра, состоящие из небольшого количества атомов и ионов, являются промежуточным продуктом при образовании наночастиц $\mathrm{Ag}$ из атомов и ионов серебра $[2,5,10-18]$. Структура и оптические свойства молекулярных кластеров серебра существенно отличаются от структуры и свойств наночастиц $\mathrm{Ag}[5]$. Небольшие молекулярные кластеры $\mathrm{Ag}$ поглощают свет в УФ диапазоне и демонстрируют высокие люминесцентные свойства $[1,2,12,14,15,19]$, что может быть использовано в биомедицинских и сенсорных приложениях $[2,14,17]$.

Молекулярные кластеры серебра способны взаимодействовать друг с другом и окружающей средой и во многих случаях необходима их стабилизация. Эти кластеры могут быть стабильны в среде инертных газов [20-22] или сохраняться после их формирования внутри матрицы стекла $[1,2,23]$. В ряде работ $[13-15,24,25]$ стабилизация молекулярных кластеров серебра в растворах была достигнута путем применения различных, главным образом, сера-содержащих органических лигандов. Тем не менее проблема стабилизации молекулярных кластеров серебра является актуальной.

Небольшие добавки серебра способны существенно улучшить различные характеристики материалов. В [26,27] было показано, что материалы на основе наночастиц оксида цинка и содержащие различные структурные формы серебра (ионы, молекулярные кластеры, наночастицы) перспективны для использования в качестве фотокатализаторов и обладают высокими антибактериальными свойствами. При взаимодействии с наночастицами серебра наблюдается заметное усиление люминесцентных свойств $\mathrm{ZnO}$ [26], увеличивается способность материала к фотогенерации синглетного кислорода [28].

Целью настоящей работы являлось исследование влияния УФ облучения на формирование молекулярных кластеров и наночастиц серебра в водных растворах, содержащих нитраты цинка и магния и поливинилпирролидон, а также в композиционных и оксидных покрытиях, полученных на основе этих растворов. 


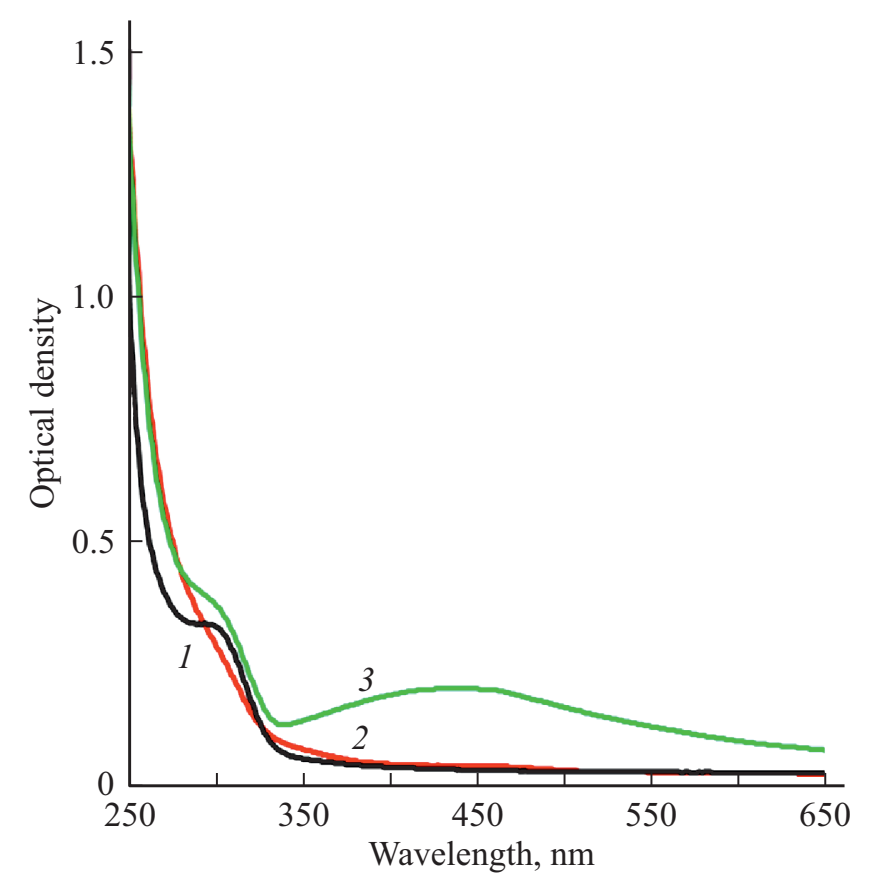

Рис. 1. Спектры поглощения раствора 2: свежеприготовленного (кривая 1), выдержанного в течение 14 дней без облучения (2) и с УФ облучением в течение 10 мин (3).

\section{Материалы и методы}

Для изготовления пленкообразующих композиций водные растворы $\mathrm{Zn}\left(\mathrm{NO}_{3}\right)_{2}, \mathrm{Mg}\left(\mathrm{NO}_{3}\right)_{2}$ и $\mathrm{AgNO}_{3}$ смешивались в заданных объемах с раствором высокомолекулярного поливинилпирролидона (ПВП) $\left(M_{w}=1300000\right.$; Sigma-Aldrich) в пропаноле-2. Полученная смесь тщательно перемешивалась в течение $30 \mathrm{~min}$. Химические составы растворов представлены в таблице.

Нанесение покрытий на поверхность плоских пластин из щелочносиликатного стекла осуществлялась путем их окунания в растворы с последующим извлечением. Сушка образцов осуществлялась при комнатной температуре. В результате сушки на поверхности стекол были сформированы композиционные покрытия, состоящие из ПВП матрицы, содержащей частицы нитратов металлов.

Высушенные образцы подвергались термообработке при $550^{\circ} \mathrm{C}$. Использованный режим термообработки обеспечивает полное разложение нитратов металлов и ПВП и удаление газообразных продуктов [29].

Измерение спектров поглощения осуществлялось на спектрофотометре Perkin Elmer Lambda 900 в спектральном диапазоне 250-700 nm. Для исследования спектров фотолюминесценции применялся флуоресцентный спектрофотометр Perkin Elmer LS-50B. Измерения люминесцентных свойств проводились при комнатной температуре.

Ртутная лампа высокого давления ДРТ-240 (Россия) использовалась для УФ облучения материалов.
Химический состав пленкообразующих растворов

\begin{tabular}{c|c|c|c|c|c|c}
\hline Раствор & \multicolumn{5}{|c}{ Химический состав, wt. } \\
\cline { 2 - 7 } & $\mathrm{H}_{2} \mathrm{O}$ & Propanol-2 & $\mathrm{PVP}$ & $\mathrm{Zn}\left(\mathrm{NO}_{3}\right)_{2}$ & $\mathrm{Mg}\left(\mathrm{NO}_{3}\right)_{2}$ & $\mathrm{AgNO}_{3}$ \\
\hline 1 & 53.03 & 37.90 & 1.45 & 7.54 & 0.07 & 0.01 \\
2 & 54.27 & 42.61 & 2.26 & 0.65 & 0.06 & 0.15
\end{tabular}

Плотность мощности излучения составляла $0.25 \mathrm{~W} / \mathrm{cm}^{2}$. Спектр излучения лампы приведен в [30].

Исследование морфологии полученных оксидных покрытий проводилось методом электронно-микроскопического анализа на приборе VEGA3 TESCAN.

\section{Экспериментальные результаты и обсуждения}

В спектрах поглощения всех изготовленных растворов до их УФ облучения наблюдается полоса с максимумом $\lambda_{\max }=300-305 \mathrm{~nm}$ (рис. 1). В свежеприготовленных растворах (рис. 1, кривая 1 ) поглощение в этой области спектра может связано только с поглощением света присутствующими в растворах нитрат-анионами, имеющими характерную полосу поглощения с $\lambda_{\max }=305$ нм [31].

После смешения растворов нитратов металлов с раствором ПВП и временной выдержке полученной смеси даже в отсутствие внешнего УФ облучения начинают протекать процессы восстановления ионов $\mathrm{Ag}^{+}$, которые приводят к формированию наночастиц серебра в растворах [32,33]. При этом промежуточными продуктами в этом фотохимическом процессе являются нейтральные атомы и различные молекулярные кластеры серебра. Формирующиеся в растворе маленькие молекулярные кластеры $\operatorname{Ag}_{n}(n<5)$ имеют полосы поглощения в спектральном интервале 270-405 nm [21,22,34]. Поэтому в исследованных нами смешанных растворах поглощение света в УФ области спектра $(\lambda=250-350 \mathrm{~nm})$ может складываться из поглощения света нитрат-анионами $\mathrm{NO}_{3}^{-}$, имеющими полосу поглощения с $\lambda_{\max } \sim 305 \mathrm{~nm}[31]$, и поглощения света различными молекулярными кластерами серебра $\mathrm{Ag}_{n}$ $(n<5)$ [1,21,22,34] (рис. 1, кривая 2).

При УФ облучении нитратных растворов интенсивность полосы поглощения нитрат-анионов с $\lambda_{\max }=305 \mathrm{~nm}$ должна уменьшаться вследствие фоторазложения этих анионов [31,35]. Вместе с тем из данных рис. 1 (кривая 3) видно, что экспериментально наблюдается увеличение поглощения растворов в этом спектральном диапазоне. При этом увеличение продолжительности УФ облучения приводит к росту интенсивности поглощения света.

Об образовании наночастиц серебра в растворе при УФ облучении свидетельствует появление широкой плазмонной полосы поглощения с $\lambda_{\max }=420 \mathrm{~nm}[36]$ и постепенный рост ее интенсивности с увеличением про- 

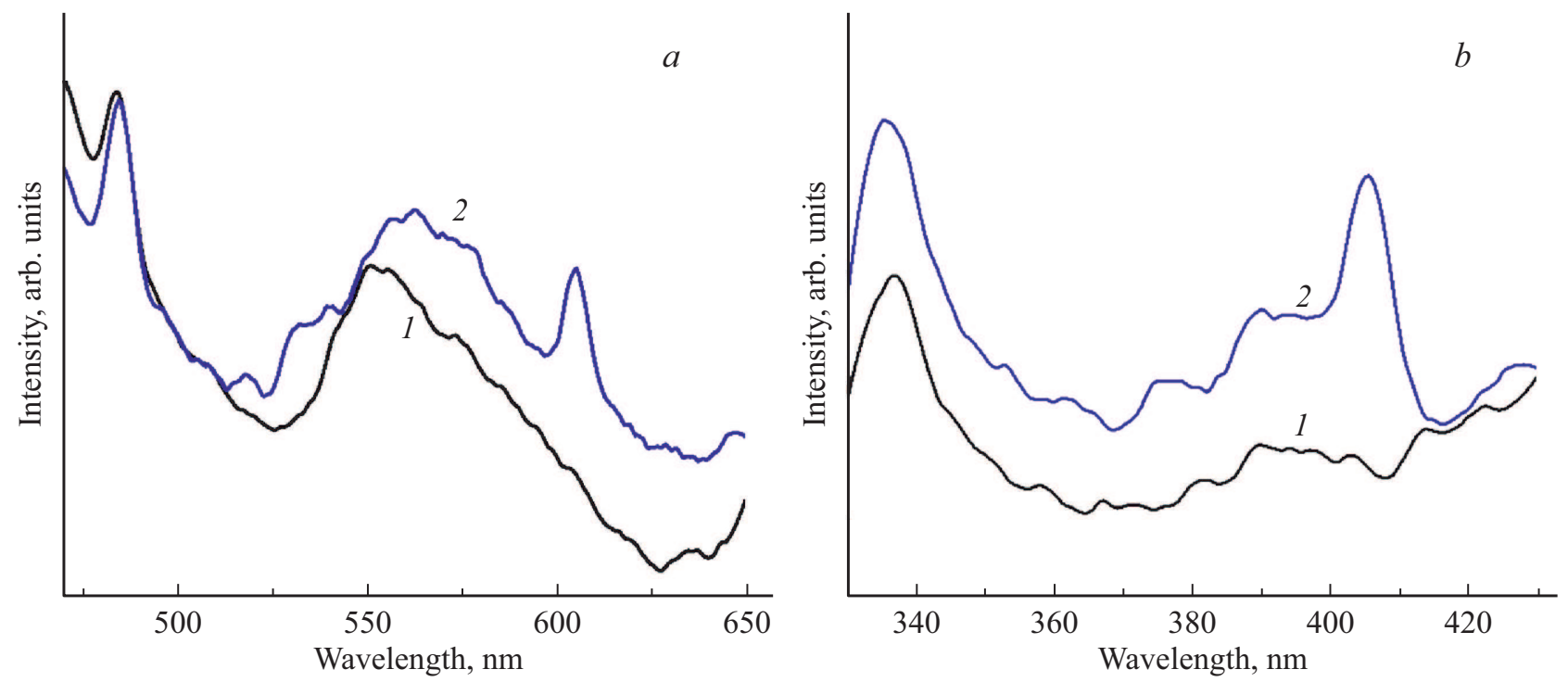

Рис. 2. Спектры фотолюминесценции $\left(\lambda_{\mathrm{ex}}=405 \mathrm{~nm}, a\right)$ и возбуждения люминесценции $\left(\lambda_{\mathrm{em}}=605 \mathrm{~nm}, b\right)$ раствора $\mathbf{1}$, выдержанного после смешения компонентов в течение $15 \mathrm{~min}$ без УФ облучения (1) и при УФ облучении (2).
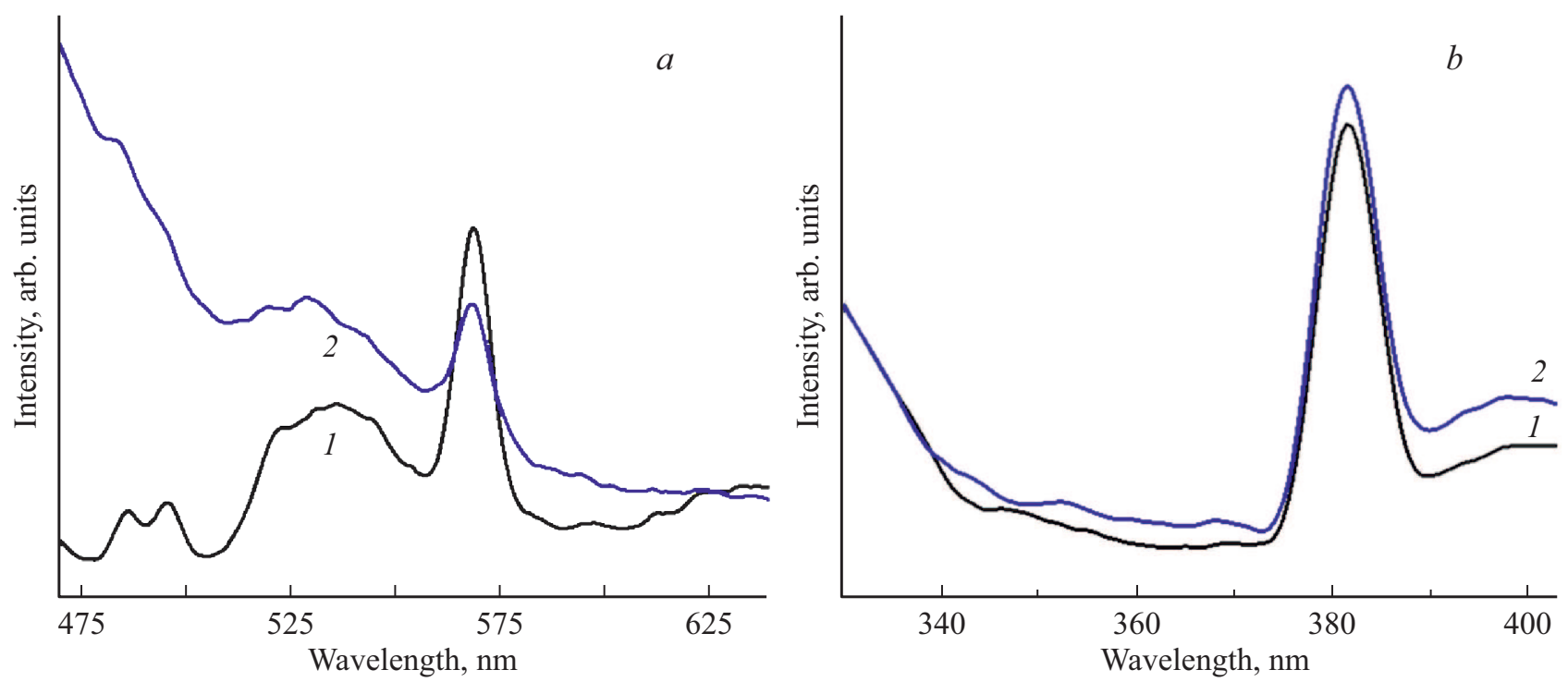

Рис. 3. Спектры фотолюминесценции $\left(\lambda_{\mathrm{ex}}=380 \mathrm{~nm}, a\right)$ и возбуждения люминесценции $\left(\lambda_{\mathrm{em}}=570 \mathrm{~nm}, b\right)$ композиционного покрытия, полученного из необлученного раствора 2 (кривая 1) и из раствора, экспонированного в течение 15 min УФ излучением сразу после смешения исходных компонентов (кривая 2).

должительности УФ облучения. Аналогичные изменения в спектральных свойствах Аg-содержащих растворов описаны ранее в [36-39].

Рис. 2 демонстрирует влияние УФ облучения на спектры фотолюминесценции $\left(\lambda_{\mathrm{ex}}=405 \mathrm{~nm}\right)$ раствора 1. Существенные различия наблюдаются как в спектрах эмиссии (рис. $2, a$ ), так и возбуждения люминесценции (рис. $2, b$ ). Фотолюминесценция раствора в спектральном диапазоне $450-650 \mathrm{~nm}$ связана с формированием в них маленьких молекулярных кластеров серебpa $[1,22,34]$. Большая интенсивность полос эмиссии и возбуждения люминесценции в спектрах раствора, под- вергнутого УФ облучению, свидетельствует о большей концентрации в нем сформировавшихся молекулярных кластеров серебра.

Влияние УФ облучения пленкообразующих растворов проявляется и в спектрах фотолюминесценции сформированных из них композиционных покрытий (рис. 3). Из рисунка видно, что в спектрах люминесценции композиционных покрытий, сформированных из предварительно облученного раствора, полосы люминесценции в спектральном диапазоне $470-550 \mathrm{~nm}$ имеют существенно более высокую интенсивность (рис. 3,a), при этом спектры возбуждения люминесценции в покрыти- 

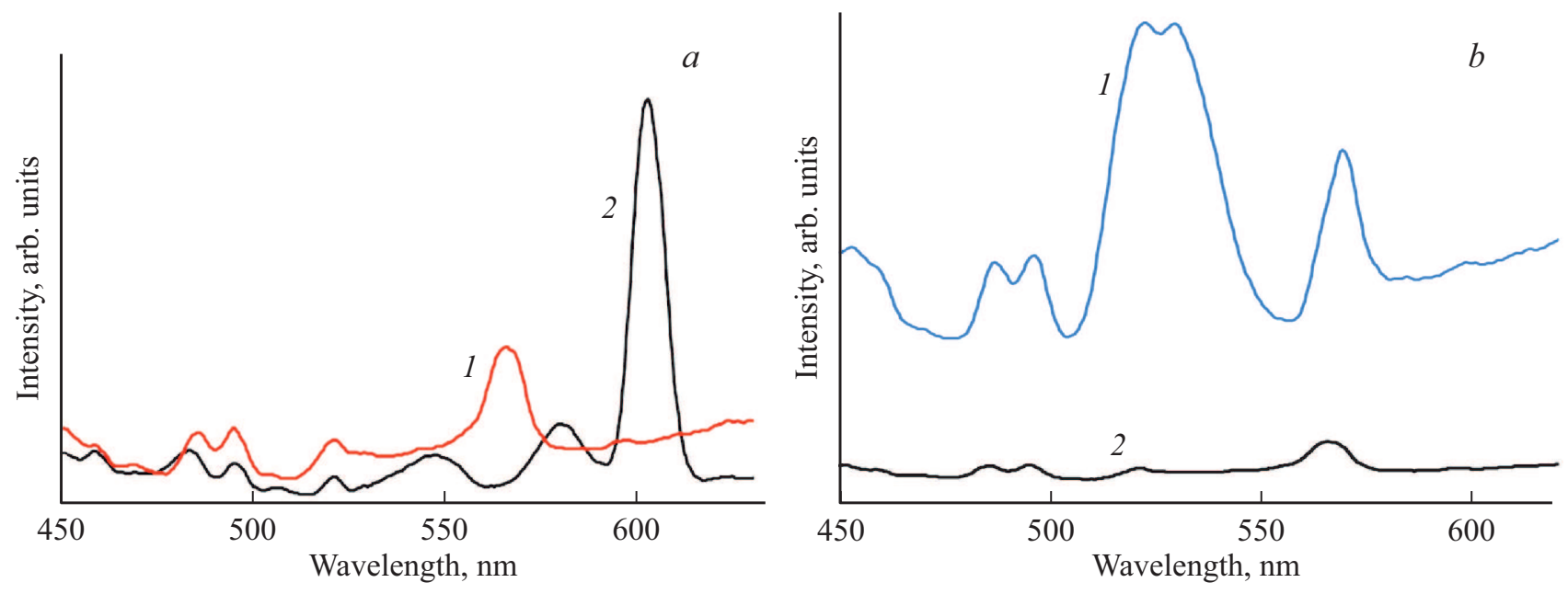

Рис. 4. Спектры фотолюминесценции: $a$ ) оксидного покрытия, изготовленного из раствора 2, подвергнутого предварительному УФ облучению в течение $30 \mathrm{~min}: \lambda_{\mathrm{ex}}=380 \mathrm{~nm}$ (кривая 1), $\lambda_{\mathrm{ex}}=405 \mathrm{~nm}$ (кривая 2) и $b$ ) композиционного покрытия, полученного из необлученного раствора 2 (кривая 1) и из раствора, экспонированного в течение 30 min УФ излучением сразу после смешения исходных компонентов (кривая 2).
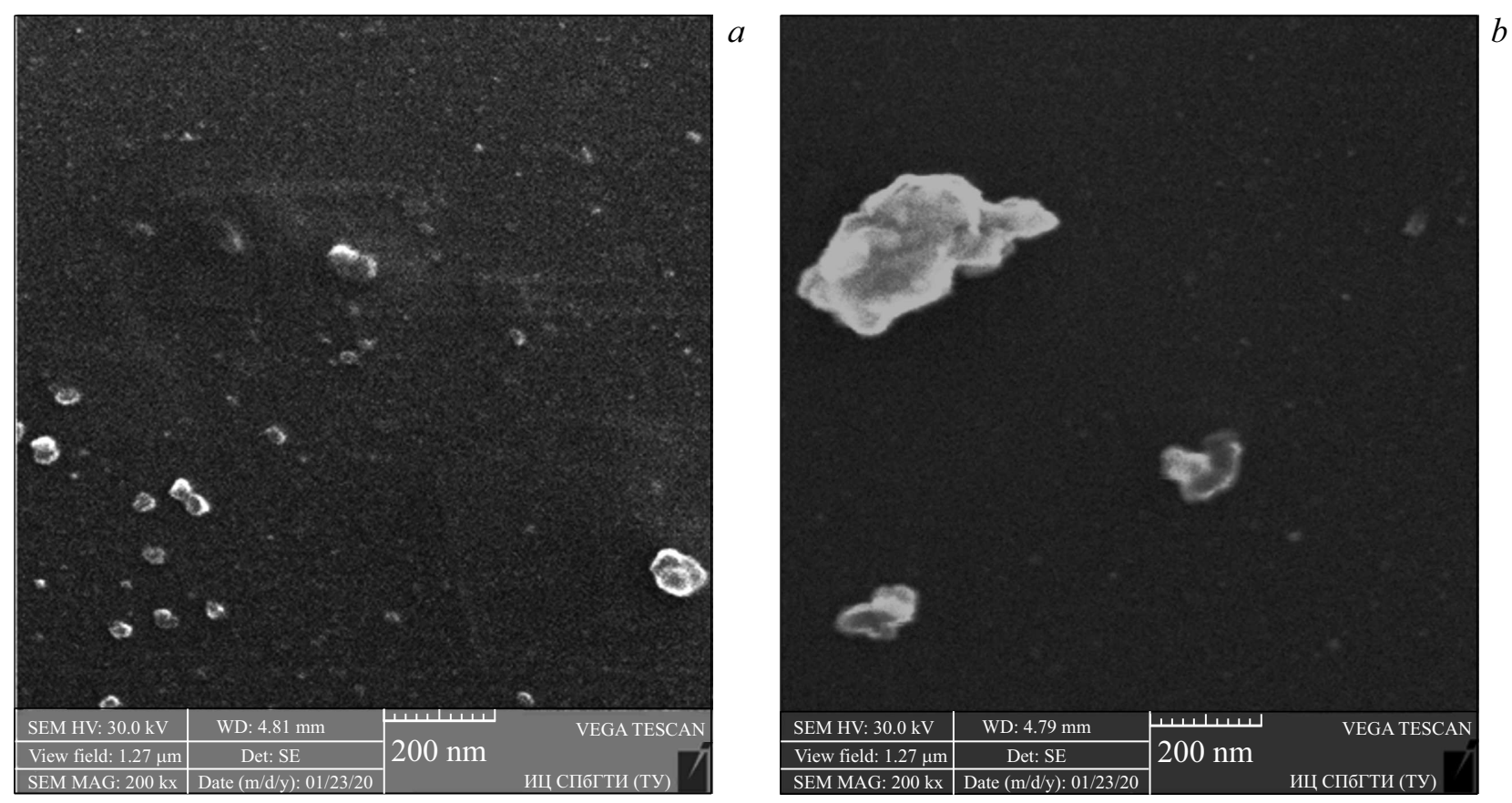

Рис. 5. Электронно-микроскопические снимки поверхности оксидных покрытий, сформированных из пленкообразующего раствора 2: исходного $(a)$ и подвергнутого предварительному УФ облучению в течение $30 \mathrm{~min}(b)$.

ях в спектральном диапазоне 330-400 nm аналогичны (рис. $3, b)$.

При термообработке образцов с этими композиционными покрытиями на поверхности стекол формируется тонкое Ag-содержащее оксидное покрытие. На рис. 4, $a$ приведены спектры фотолюминесценции образца с оксидным покрытием, полученным из предварительно облученного раствора. Видно, что форма спектров, а также положение и интенсивность полос люминесценции зависят от длины волны возбуждающего излучения. Наличие наблюдаемых многочисленных полос люминесценции, а также зависимость спектров люминесценции от длины волны возбуждающего излучения свидетельствуют о присутствии различных молекулярных кластеров серебра в структуре полученных оксидных покрытий.

Влияние предварительной обработки растворов на люминесцентные свойства полученных оксидных покрытий иллюстрируется рис. 4, $b$. Видно, что интенсивность люминесценции покрытий, сформированных из пленкообразующих растворов, прошедших предварительную 
УФ обработку, значительно ниже, чем у покрытий, полученных из растворов без предварительного УФ облучения.

На рис. 5 представлены электронно-микроскопические снимки поверхности оксидных покрытий, сформированных из исходного пленкообразующего раствора (рис. 5, $a$ ) и раствора, подвергнутого предварительному УФ облучению (рис. 5, $b$ ). На обоих рисунках видны неоднородности, имеющие размер $15-30 \mathrm{~nm}$. На фотографии покрытия, полученного из предварительно облученного раствора, присутствуют также довольно крупные агрегаты, имеющие размер до 150-200 $\mathrm{nm}$. На основании приведенных данных можно сделать вывод о том, что предварительное УФ облучение пленкообразующего раствора приводит к формированию оксидных покрытий, содержащих более крупные неоднородности.

\section{Заключение}

Сформированные полимерно-солевым методом на поверхности стекол композиционные и оксидные покрытия, содержащие различные структурные формы серебра, характеризуются высокой однородностью, прозрачностью в видимой области спектра и люминесцентными свойствами. УФ облучение значительно ускоряет процессы эволюции различных структурных форм серебра в водных растворах, композиционных органонеорганических и оксидных покрытиях, существенно изменяя спектрально-люминесцентные свойства материалов.

\section{Финансирование работы}

Работа была частично (Евстропьев С.К.) поддержана грантом Российского научного фонда № 19-19-00596.

\section{Конфликт интересов}

Авторы заявляют, что у них нет конфликта интересов.

\section{Список литературы}

[1] Dubrovin V.D., Ignatiev A.I., Nikonorov N.V., Sidorov A.I., Shakhverdov T.A., Agafonova D.S. // Opt. Mater. 2014. V. 36. N 4. P. 753.

[2] Agafonova D.S., Kolobkova E.V., Ignatiev A.I., Nikonorov N.V., Shakhverdov T.A., Shirshnev P.S., Sidorov A.I., Vasiliev V.N. Opt. Engineering. 2015. V. 54. N 11. P. 117107.

[3] Рыбалтовский А.О., Аксенов А.А., Нерасимова В.И., Зосимов В.В., Попов В.К., Соловьева А.Б., Тимашев П.С., Баграташвили В.Н. // Сверхкритические флюиды: Теория и практика. 2008. Т. 3. № 1. С. 50.

[4] Евстропьев С.К., Никоноров Н.В., Киселев В.М., Саратовский А.С., Колобкова Е.В. // Опт. и спектр. 2019. T. 127. B. 2. C. 292; Evstropiev S.K., Nikonorov N.V., Kiselev V.M., Saratovskii A.S., Kolobkova E.V. // Opt. Spectrosc. 2019. V. 127. N 2. P. 314.

[5] Ozin G.A., Huber H. // Inorg. Chem. 1978. V. 17. N 1. P. 155.
[6] Zaarour M., El Roz M., Dong B., Retoux R., Aad R., Cardin J., Dufour C., Gourbilleau F., Gison J.-P., Mintova S. // Langmuir. 2014. V. 30. N 921. P. 6250. doi10.1021/la5006743. Hal-01138057

[7] Kshirsagar P., Sangaru S.S., Malvindi M.A., Martiradonna L., Gingolani R., Pompa P.P. // Colloid and Surfaces A.: Physicochem. and Engineering Aspects. 2011. V. 392. N 1. P. 264.

[8] Silvert P.-Y., Herrera-Urbina R., Duvaauchelle N., Vijayakrishnan V., Tekaia-Elhsissen K.J. // Mater. Chem. 1996. V. 6. P. 573.

[9] Huang Tao, Xu Xiao-Hong Nancy // J. Mater. Chem. 2010. V. 20. P. 9867.

[10] Petit C., Lixon P., Pileni M.-P. // J. Phys. Chem. 1993. V. 97. P. 12974.

[11] Pelton M., Tang Yun, Bakr O.M., Stellacci F. // J. Am. Chem. Soc. 2012. V. 134. N 29. P. 11856.

[12] Ramsay H.S., Silverman M.M., Simon D., Oleschuk R.D., Stamplecoskie K.G. // Nanoscale. 2019. V. 11 P. 20522. doi 10.1039/C9NR07626c

[13] Cathcart N., Mistry P., Makra C., Pietrobon B., Coombs N., Jelokhani-Niaraki M., Kitaev V. // Langmuir. 2009. V. 25 (10). P. 5840.

[14] Guéve X.L., Spies C., Schneider-Daum N., Jung G., Scheneder M. // Nano Research. 2014. V. 5. N 6. P. 379.

[15] Yang T., Dai S., Tan H., Zong Y., Liu Y., Chen J., Zhang K., Wu P., Zhang S., Xu J., Tian Y. // J. Phys. Chem. C. 2019. V. 123 (30). P. 18638.

[16] Jia Xiaofang, Li Jing, Wang Erkang. // Chem. Commun. 2014. V. 50. P. 9565.

[17] Luo Zhentao, Zheng Kaiyuan, Xie Jianping. // Chem. Commun. 2014. V. 50. P. 5134.

[18] Harb M., Rabilloud F., Simon D., Rydlo A., Lecoultre S., Conus F., Rodrigues V., Félix C. // J. Chem. Phys. 2008. V. 129. 194108. doi 10.1063/1.3013557

[19] Fageria P., Gangopadhyay S., Pande S. // RSC Adv. 2014. V. 4. P. 24962. doi 10.1039/c4ra03158j

[20] Fedrigo S., Harbich W., Buttet J. // Int. J. Modern Phys. 1992. V. $6(23-24)$. P. 3767-3771.

[21] Lecoultre S., Rydlo A., Buttet J., Félix C., Gilb S., Harbich W. // J. Chem. Phys. 2011. V. 134. P. 184504. doi 10.1063/1.3589357

[22] Harbich W., Fedrigo S., Meyer F. // J. Chem. Phys. 1990. V. 93. P. 8535. doi 10.1063/1.459291

[23] Nedyalkov N., Dikovska A., Koleva M., Stankova N., Nikov R., Borisova E., Genova Ts., Aleksandrov L., Iordanova R., Terakawa M. // Opt. Mater. 2020. V. 100. P. 109618. doi 10.1016/j.optmat.2019.109618

[24] Sahu D.K., Sarkar P., Singha D., Sahu K. // RSC Adv. 2019. V. 9. P. 39405-39409.

[25] Van der Linden M., Barendregt A., Van Bunningen J., Chin P.T.K., Thies-Weesie D., De Groot F.M.F., Meijerink A. // Nanoscale. 2016. V. 8. P. 19901.

[26] Cheng Z., Zhao S., Han L. // Nanoscale. 2018. V. 10. P. 6892.

[27] Guidelli E.J., Baffa O., Clarke D.R. // Sci. Rep. 2015. V. 5. P. 14004.

[28] Багров И.В., Киселев В.М., Евстропьев С.К., Саратовский А.С., Демидов В.В., Матросова А.В. // Опт. и спектр. 2020. T. 128. B. 2. C. 218. doi 10.21883/OS.2020.02.48963.281-19 
[29] Evstropiev S.K., Soshnikov I.P., Kolobkova E.V., Evstropyev K.S., Nikonorov N.V., Khrebtov A.I., Dukelskii K.V., Kotlyar K.P., Oreshkina K.V., Nashekin A.V. // Opt. Mater. 2018. V. 82. P. 81.

[30] Evstropiev S.K., Vasilyev V.N., Nikonorov N.V., Kolobkova E.V., Volkova N.A., Boltenkov I.S. // Chem. Engineering and Processing: Process Intensification. 2018. V. 134. P. 45. doi 10.1016/j.cep.2018.10.020

[31] Mack J., Bolton J.R. // J. Photochem. Photobiol. A: Chem. 1999. V. 128. P. 1.

[32] Wang Hongshui, Qiao Xueliang, Chen Jianguo, Wang Xiaojian, Ding Shiyuan. // Mater. Chem. Phys. 2005. V. 94. P. 449.

[33] Kan Caixia, Cai Weiping, Li Cuncheng, Zhang Lide. // J. Mater. Res. 2005. V. 20. N 7. P. 320.

[34] Столяриук М.В., Сидоров А.И. // ОПт. и спектр. 2018. T. 125. B. 3. C. 291. Stolyarchuk M.V., Sidorov A.I. // Opt. Spectrosc. 2018. V. 125. N 3. P. 305.

[35] Sharpless C.M., Linden K.G. // Environ. Sci. Technol. 2001. V. 35. N 14. P. 2949.

[36] Schasfoort R.B.M., Tudos A.J. Handbook of Surface Plasmon Resonance, RSC Publishing, 2008.

[37] Silvert P.-Y., Herrera-Urbina R., Tekaia-Elhsissen K. // J. Mater. Chem. 1997. V. 7. N 2. P. 293-299.

[38] Huang Tao, Xu Xiao-Hong Nancy. // J. Mater. Chem. 2010. V. 20. P. 9867.

[39] Истомина О.В., Евстропьев С.К., Колобкова Е.В., Тробимов А.О. // Опт. и спектр. 2018. Т. 124. В. 6. C. 742. Istomina O.V., Evstropiev S.K., Kolobkova E.V., Trofimov A.O. // Opt. Spectrosc. 2018. V. 124. N 6. P. 774. 